\title{
FORMULASI MULTIGRANUL SALUT FILM DALAM KAPSUL UNTUK PELEPASAN OBAT SECARA TERKENDALI
}

\author{
Wirabrata*1 $^{* 1}$ \\ Program Studi Farmasi, Fakultas Farmasi, Universitas Pancasila, \\ Lenteng Agung, Jakarta Selatan, 12640 \\ wira.brata@yahoo.com
}

\begin{abstract}
ABSTRAK
Penelitian ini tentang formulasi multigranul salut film dalam kapsul yang bertujuan memberikan pelepasan obat secara terkendali dengan bahan berkhasiat gliseril guaikolat. Multigranul yang digunakan terdiri dari 3 jenis granul, yaitu: 1 jenis granul tidak disalut sebagai dosis awal obat, dan 2 jenis granul salut film dengan beda konsentrasi penyalutnya. Penyalut film yang dgunakan adalah hidroksipropil metilselulosa ftalat dengan konsentrasi: $1 \%, 5 \%, 10 \%$, dan $15 \%$. Granul dibuat menggunakan Metode Panci Penyalut. Bobot granul untuk tiap kapsul adalah $450 \mathrm{mg}$ mengandung gliseril guaiakolat sebanyak $100 \mathrm{mg}$ untuk dosis awal dan $200 \mathrm{mg}$ untuk dosis penjagaan berupa variasi 2 macam granul salut film. Kemudian dibuat formula-formula kapsul dengan kombinasi dari multigranul dan dilakukan pengujian pelepasan obat. Hasil penelitian menunjukkan bahwa: kapsul Formula 1 dan Formula 6 tidak memberikan profil pelepasan obat secara terkendali. Kapsul Formula 2 memberikan profil pelepasan obat secara terkendali selama 8 jam. Kapsul Formula 3 memberikan profil pelepasan obat secara terkendali selama 12 jam dengan jumlah obat terlarut yang terbesar, yaitu: 92,9\%. Kapsul Formula 4 dan Formula 5 memberikan pelepasan obat secara terkendali selama 12 jam dengan jumlah obat terlarut 91,5\% dan 89,2\%. Kesimpulan diperoleh formula terbaik untuk pelepasan terkendali dari multigranul dalam kapsul yang paling lama secara uji disolusi.
\end{abstract}

Kata kunci: formulasi, lepas terkendali, multigranul, salut film.

\begin{abstract}
This research is about a multigranul film-coated capsule formulation which aims to provide controlled release of the drug with the active ingredient glyceryl guaikolate. The multigranules used consisted of 3 types of granules, namely: 1 type of non-coated granule as the initial dose of the drug, and 2 types of film-coated granule with different coating concentrations. The film coating used was hydroxypropyl methylcellulose phthalate with the following concentrations: $1 \%, 5 \%$, $10 \%$, and $15 \%$. The granules are made using the Coating Pan Method. The weight of the granules for each capsule is $450 \mathrm{mg}$ containing glyceryl guaiacolate as much as $100 \mathrm{mg}$ for the initial dose and $200 \mathrm{mg}$ for the maintenance dose in the form of variations of 2 kinds of film-coated granules. Then capsule formulas are made with a combination of multigranules and drug release testing is carried out. Results were obtained: Formula 1 and Formula 6 capsules did not provide a controlled drug release profile. Formula 2 capsules provide a controlled drug release profile for 8 hours. Formula 3 capsules provide a controlled release profile for 12 hours with the largest amount of dissolved drug, namely: 92.9\%. The Formula 4 and Formula 5 capsules provide controlled drug release for 12 hours with a dissolved drug amount of $91.5 \%$ and $89.2 \%$. The conclusion was obtained that the best formula for controlled release of multigranules in capsules was the longest by dissolution test.
\end{abstract}

Key words: formulation, controlled release, multigranules, film coating,.

\section{PENDAHULUAN}

Gliseril guaiakolat (GG) adalah zat aktif termasuk obat golongan ekspektoran, yaitu obat yang dapat merangsang pengeluaran dahak dari saluran napas (ekspektorasi). Zat aktif ini diabsorpsi baik di saluran cerna dan cepat diekskresi melalui urin; lebih stabil dalam bentuk padat daripada dalam bentuk cair; memiliki waktu paruh yang sangat pendek 
yaitu: 1 jam dan tidak terdeteksi dalam darah 8 jam setelah pemberian; dosis lazim satu kali pakai 100-200 mg diulang tiap 2-4 jam, sehingga sangat baik untuk dibuat menjadi sediaan lepas lambat, maupun lepas terkendali, baik dalam bentuk kapsul maupun tablet [1].

Salah satu cara untuk memperpanjang masa kerja obat yakni dengan membuat pelepasan obat secara berulang. Pelepasan obat secara berulang ini dapat dikendalikan sesuai dengan tujuan dari sediaan yang dibuat. Cara membuat pelepasan obat secara terkendali dapat dilakukan dengan cara penyalut granul. Granul yang disalut akan memberikan pelepasan berkelanjutan [2].

Pada suatu sistem penyalutan dengan konsentrasi bahan penyalut yang bervariasi, dapat dihasilkan suatu pelepasan obat yang diinginkan, misalnya penyalutan untuk pelepasan obat di lambung, penyalutan enterik untuk pelepasan obat di usus, dimana efek terapi diinginkan. Pada penyalutan khusus dapat dihasilkan pelepasan obat dengan aksi berulang atau pelepasan dipertahankan dari suatu dosis tunggal untuk 8-12 jam.

Pada umumnya dalam Bidang Farmasi, penyalutan selalu diasosiasikan dengan penyalutan tablet, sedangkan dalam kenyataannya, penyalutan dikerjakan pula untuk granul. Proses penyalutan lapisan tipis dalam Bahasa Inggris dikenal sebagai Film Coating merupakan salah satu cara penyalutan yang ada, meliputi penempelan lapisan polimer yang membentuk membran uniform pada permukaan sediaan farmasi yang dapat berbentuk granul. Dengan menggunakan sistem salut film, dosis obat dapat dilepaskan berkelanjutan, kandungan obat bisa relatif tinggi [4].

Bahan dasar utama penyalutan lapisan tipis adalah polimer pembentuk film. Hidroksipropil metilselulosa ftalat sebagai material penyalut tipis merupakan salah satu diantara polimer sintetis yang banyak digunakan untuk tujuan penyalutan lapisan tipis sediaan salut enterik karena bersifat gastroresisten. Penggunaan pada berbagai variasi konsentrasi bahan penyalut pada sistem penyalutan granul dapat dihasilkan profil pelepasan obat dengan aksi berulang. Bentuk sediaan pelepasan terkontrol sangat penting ketikat tingkat pelepasan obat mempengaruhi kefektifan terapi [5].

Sistem penyalutan granul menghasilkan granul dalam bentuk tersalut. Salah satu cara yang praktis untuk mengemas granul dapat dilakukan dengan memasukkan granul dalam cangkang kapsul. Metode penyalutan granul akan memberikan sediaan pelepasan terkontrol yang dapat diatur lajut pelepasan obatnya [6].

Kapsul didefinisikan sebagai bentuk sediaan padat (berbentuk serbuk/campuran serbuk, granul, atau cairan), dimana satu macam bahan obat atau lebih dan atau tidak mengandung bahan inert seperti pewarna dimasukkan ke dalam cangkang atau wadah kecil yang umumnya terbuat dari gelatin yang memiliki banyak keunggulan dibanding sediaan obat yang lain. Bentuk sediaan praktis dengan pelepasan instan, yang dapat dikembangkan lebih lanjut menjadi pelepasan terkontrol dengan mencampurkan polimer film [7].

Berdasarkan hal tersebut di atas, dilakukan penelitian tentang formulasi sediaan padat bentuk kapsul dengan pelepasan obat secara terkendali atau terkontrol melalui sistem penyalutan granul dengan bahan berkhasiat GG dan bahan penyalut hidroksipropil metilselulosa ftalat.

Penelitian ini bertujuan untuk membuat formula multigranul salut film dalam kapsul dengan bahan berkhasiat GG dengan mekanisme penyalutan granul yang bervariasi konsentrasi dapat memberikan pelepasan obat secara terkendali.

Manfaat dari penelitian ini adalah penelitian ini sebagai informasi formulasi multigranul salut film dalam kapsul dengan pelepasan obat secara terkendali dan penelitian ini menjadi salah satu solusi dalam upaya meningkatkan kepatuhan pasien terhadap aturan pemakaian obat (patient compliance), serta akan sangat bermanfaat bagi pasien karena dapat mengurangi frekuensi pemakaian obat dan secara tidak langsung dapat mengurangi efek samping obat.

\section{METODOLOGI PENELITIAN}

Prinsip penelitian adalah penelitian eksperimental dengan cara pembuatan granul dengan atau tanpa disalut. Bahan penyalutan granul yang digunakan berbeda konsentrasi $1 \%, 5 \%, 10 \%$, dan $15 \%$. Kemudian dilakukan pengujian granul dan pengujian kapsul yang berisi kombinasi 3 macam granul.

Bahan yang digunakan: GG BPFI, GG (bahan baku), HPMCP, avicel pH 101, pati jagung, talk, magnesium stearat, zat warna Brilliant blue FCF (pewarna biru), zat warna Ponceau SX (pewarna merah), metilenklorida, etanol 95\%, kloroform, aquadest, cangkang kapsul no. 0 (bagian atas warna hitam dan bagian bawah transparan warna ungu), titan 
dioksida, dan niaset (mengandung minyak biji jarak).

Alat yang digunakan: timbangan analitik (Sartorius), timbangan mikro (Mettler MT 5), moisturemeter Karl Fischer (Mitsubishi CA06), seperangkat alat coating Kikusui Seisakusho LTD (Japan), spektrofotometer Shimadzu UV 160, spektrofotometer Infra Red Shimadzu IR 406, stopwatch, alat uji kemampatan (Stamp volumeter), alat uji waktu hancur kapsul (Omron H3BA), alat uji disolusi (Erweka DT 6), alat uji aliran, termometer, ayakan nomor nominal 10,14, 16, 18, 60, alat semprot (China) dan kompresor (China), dan alat-alat gelas.

Tahapan penelitian seperti pada Gambar 1 berikut.

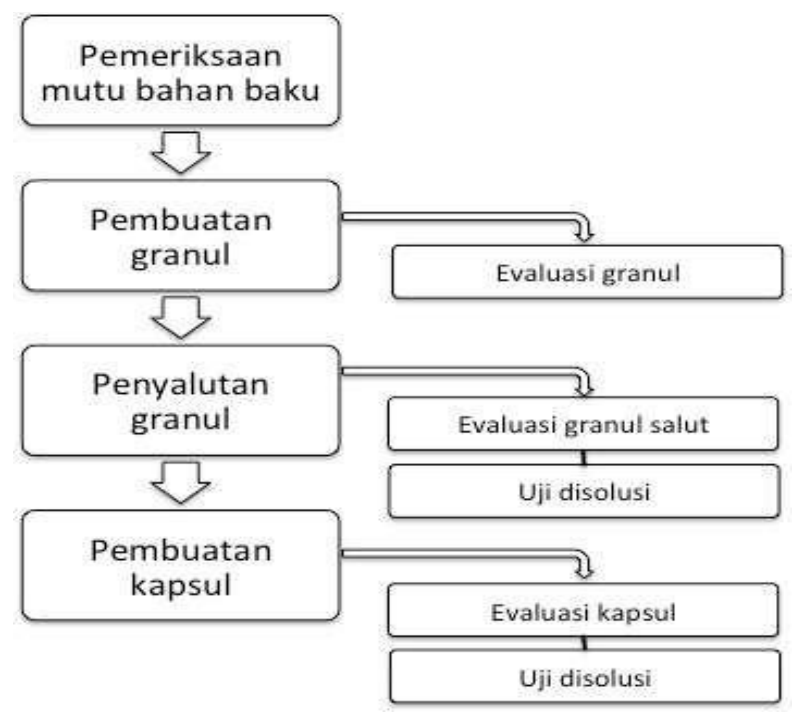

Gambar 1. Skema Tahap Penelitian

\section{Metode}

Pemeriksaan mutu bahan baku, yaitu: bahan berkhasiat GG dan bahan tambahan: HPMCP (55), avicel pH 101, pati jagung, magnesium stearat, dan talk menurut Farmakope Indonesia Edisi III, dan Edisi IV, serta The United States Pharmacopeia XXIII. Dilanjutkan dengan penetapan panjang gelombang serapan maksimum GG, penentuan stabilitas serapan GG dalam larutan, pengukuran serapan bahan tambahan pada panjang gelombang serapan maksimum, dan pembuatan kurva kalibrasi GG.

Pembuatan granul dengan Metode Granulasi Basah dan evaluasi granul (kadar air, waktu alir, sudut diam, kompresibilitas, uji homogenitas, keseragaman derajat halus, distribusi ukuran granul, penetapan bobot jenis, penetapan kadar, dan disolusi).

Penyalutan granul dengan Metode Panci Penyalut dan evaluasi granul salut (homogenitas warna, distribusi ukuran granul, penetapan kadar, dan disolusi).

Pembuatan kapsul, yaitu pencampuran 3 jenis granul dilakukan dengan manual menggunakan sendok pengaduk dan memasukkan campuran granul ke dalam cangkang kapsul dengan menggunakan mesin pengisi kapsul yang dijalankan secara manual, evaluasi kapsul (keragaman bobot, waktu hancur, homogenitas campuran granul, penetapan kadar, dan disolusi akhir). Karakter berkelanjutan in-vitro dari zat aktif diselidiki dalam simulasi cairan pencernaan. (Dou, 2019)

Penetapan panjang gelombang serapan maksimum GG, sejumlah lebih kurang $25 \mathrm{mg}$ GG ditimbang saksama, dimasukkan ke dalam labu tentukur 25-ml, ditambahkan medium disolusi sampai tanda, kocok. Sejumlah $2 \mathrm{ml}$ larutan tersebut dipipet ke dalam labu tentukur 50-ml, diencerkan dengan medium disolusi sampai tanda, lalu dikocok hingga homogen. Serapan larutan diukur pada panjang gelombang 200-300 nm.

Penentuan stabilitas serapan GG dalam larutan (operating time), sejumlah lebih kurang 25 mg GG ditimbang saksama, dimasukkan ke dalam labu tentukur 25-ml, ditambahkan medium disolusi sampai tanda, kocok. Sejumlah $2 \mathrm{ml}$ larutan tersebut dipipet ke dalam labu tentukur 50-ml, diencerkan dengan medium disolusi sampai tanda, lalu dikocok hingga homogen. Stabilitas serapan dibaca pada panjang gelombang $273 \mathrm{~nm}$. Pembacaan serapan diulang setipa 10 menit sebanyak 12 kali pembacaan. 
Pengukuran serapan bahan pembantu pada panjang gelombang maksimum, sejumlah avicel pH 101, pati jagung, talk, dan magnesium stearat ditimbang saksama masing-masing lebih kurang setara dengan bobot yang terkandung dalam kapsul. Masing-masing bahan pembantu tersebut dimasukkan ke dalam labu tentukur 100-ml, dan dilarutkan dengan medium disolusi sampai tanda, kocok hingga homogen. Larutan tersebut disaring dengan kertas saring, beberapa $\mathrm{ml}$ filtrat pertama dibuang. Kemudian filtrat selanjutnya dipipet $5 \mathrm{ml}$, dimasukkan ke dalam labu tentukur 50-ml, dan diencerkan dengan medium disolusi sampai tanda, lalu dikocok hingga homogen. Serapan larutan diukur pada panjang gelombang $273 \mathrm{~nm}$.

Pembuatan kurva kalibrasi GG, sejumlah lebih kurang $25 \mathrm{mh}$ GG ditimbang saksama, dimasukkan ke dalam labu tentukur 25-ml, ditambahkan kloroform sampai tanda, kocok.
Sejumlah $1 \mathrm{ml}, 2 \mathrm{ml}, 3 \mathrm{ml}, 4 \mathrm{ml}, 5 \mathrm{ml}$, dan $6 \mathrm{ml}$ larutan tersebut dipipet ke dalam labu tentukur 100-ml, masing-masing diencerkan dengan kloroform sampai tanda, lalu dikocok hingga homogen. Kemudian serapan dari masingmasing konsentrasi di atas diukur pada panjang gelombang $276 \mathrm{~nm}$ dengan menggunakan kloroform sebagai blangko. Sejumlah lebih kurang $25 \mathrm{mh}$ GG ditimbang saksama, dimasukkan ke dalam labu tentukur 25-ml, ditambahkan kloroform sampai tanda, kocok. Sejumlah $1 \mathrm{ml}, 2 \mathrm{ml}, 3 \mathrm{ml}, 4 \mathrm{ml}, 5 \mathrm{ml}$, dan $6 \mathrm{ml}$ larutan tersebut dipipet ke dalam labu tentukur 100-ml, masing-masing diencerkan dengan kloroform sampai tanda, lalu dikocok hingga homogen. Kemudian serapan dari masingmasing konsentrasi di atas diukur pada panjang gelombang $273 \mathrm{~nm}$ dengan menggunakan kloroform sebagai blangko.

Tabel 1. Formula Kapsul GG

\begin{tabular}{|c|c|c|c|c|c|c|c|c|c|c|c|c|}
\hline \multirow{2}{*}{ No. } & \multirow{2}{*}{ Bahan } & \multicolumn{11}{|c|}{ Formula kapsul } \\
\hline & & A & B & C & $D$ & $\mathrm{E}$ & 1 & 2 & 3 & 4 & 5 & 6 \\
\hline 1. & Gliseril guaiakolat $(\mathrm{g})$ & 100 & 100 & 100 & 100 & 100 & 300 & 300 & 300 & 300 & 300 & 300 \\
\hline 2. & Avicel pH 101 (g) & 29 & 29 & 29 & 29 & 29 & 87 & 87 & 87 & 87 & 87 & 87 \\
\hline 3. & Pati jagung (g) & 15 & 15 & 15 & 15 & 15 & 45 & 45 & 45 & 45 & 45 & 45 \\
\hline 4. & Talk (g) & 3 & 3 & 3 & 3 & 3 & 9 & 9 & 9 & 9 & 9 & 9 \\
\hline 5. & Magnesium stearat $(\mathrm{g})$ & 3 & 3 & 3 & 3 & 3 & 9 & 9 & 9 & 9 & 9 & 9 \\
\hline 6. & HPMCP (\%) & - & 1 & 5 & 10 & 15 & - & 20 & 22,5 & 25 & 27,5 & 30 \\
\hline 7. & Niaset (thd. HPMCP 10\%) & - & 10 & 10 & 10 & 10 & - & 10 & 10 & 10 & 10 & 10 \\
\hline 8. & |Titan dioksida (\%) & - & 2 & 2 & 2 & 2 & - & 4 & 4 & 4 & 4 & 4 \\
\hline 9.a. & Briliant blue FCF (\%) & - & - & 2 & 2 & - & - & 4 & 3 & 2 & 1 & - \\
\hline 9.b. & Ponceau SX (\%) & - & 2 & - & - & 2 & - & - & 1 & 2 & 3 & 4 \\
\hline 10. & \begin{tabular}{|l} 
Etanol:metilen klorida \\
perbandingan 1:1 (ml)
\end{tabular} & - & 100 & 100 & 100 & 100 & - & 200 & 200 & 200 & 200 & 200 \\
\hline \multicolumn{13}{|c|}{ Keterangan tabel: } \\
\hline & \multicolumn{2}{|c|}{ - Formula A (granul tidak disalut) } & & \multicolumn{4}{|c|}{ - Formula 1 = 3 Formula $\mathrm{A}$} & & & & & \\
\hline & \multicolumn{3}{|c|}{ - Formula B (granul salut HPMCP 1\%) } & \multicolumn{5}{|c|}{ - Formula $2=1$ Formula $A+2$ Formula $D$} & & & & \\
\hline & \multicolumn{3}{|c|}{ - Formula C (granul salut HPMCP 5\%) } & \multicolumn{7}{|c|}{ - Formula $3=1$ Formula $A+1,5$ Formula $D+0,5$ Formula $E$} & & \\
\hline & \multicolumn{3}{|c|}{ - Formula D (granul salut HPMCP 10\%) } & \multicolumn{7}{|c|}{ - Formula $4=1$ Formula $A+1$ Formula $D+1$ Formula $E$} & & \\
\hline & \multicolumn{3}{|c|}{ - Formula E (granul salut HPMCP 15\%) } & \multicolumn{7}{|c|}{ - Formula $5=1$ Formula $A+0,5$ Formula $D+1,5$ Formula $E$} & & \\
\hline & & & & - Form & $6=1$ & ormula & $+2 \mathrm{Fc}$ & ula $E$ & & & & \\
\hline
\end{tabular}

\section{HASIL DAN PEMBAHASAN}

Hasil pemeriksaan bahan baku GG memenuhi syarat dengan kadar 99,31\%. Hasil pemeriksaan bahan baku HPMCP, avicel $\mathrm{pH}$ 101, pati jagung, talk, dan magnesium stearat memenuhi syarat Farmakope Indonesia Edisi IV dan The United States Pharmacopeia XXIII, sehingga dapat digunakan untuk penelitian tahap selanjutnya.

Hasil penetapan panjang gelombang serapan maksimum bahan baku GG dalam medium disolusi adalah $273 \mathrm{~nm}$, memenuhi syarat menurut Clarke's Isolation and
Identification of Drugs, 1986. Hasil penetapan menunjukkan bahwa pengukuran serapan masih dapat dilakukan 2 jam setelah pembuatan larutan sampel. Hal ini berguna pada saat uji disolusi, dimana jarak waktu pengambilan cuplikan pada formula tertentu cukup lama.

Hasil pengukuran serapan bahan tambahan kapsul GG dalam kloroform dan medium disolusi pada panjang gelombang $273 \mathrm{~nm}$ adalah 0,000. Hasil pengukuran menunjukkan bahwa bahan tambahan tidak memberikan serapan, sehingga tidak mempengaruhi pengukuran serapan pada penelitian dan perhitungan selanjutnya. 


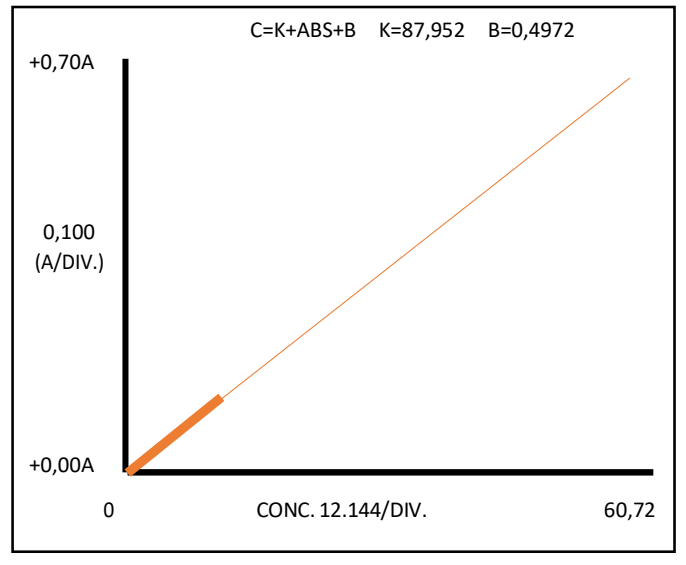

Gambar 2. Kurva kalibrasi GG (medium disolusi)

Hasil penetapan kurva kalibrasi GG dalam medium disolusi menunjukkan hubungan yang linier, persamaan $\mathrm{C}=87,953$. Abs $+0,4972$ dan koefisien korelasi 0,9997, persamaan ini digunakan pada perhitungan disolusi. Hasil penetapan kurva kalibrasi GG dalam kloroform menunjukkan hubungan yang linier, persamaan $\mathrm{C}=84,933$.Abs- 0,0215 dan koefisien korelasi 0,9999, persamaan ini digunakan pada perhitungan penetapan kadar. Kedua persamaan dapat memberikan hasil perhitungan yang teliti dan meminimalkan kesalahan perhitungan, yaitu dengan koefisien korelasi mendekati satu.

Hasil penetapan kadar air granul rata-rata $4,17 \% \mathrm{SD}=0,098$, memenuhi syarat menurut Voight, yaitu 3-5\%. Hasil ini menunjukkan bahwa granul dalam kondisi kelembaban yang cukup, sehingga pada proses pembuatan granul, granul dapat bergulir dengan baik dalam panci penyalut dan tidak lengket antara granul yang satu dengan granul yang lain.

Hasil penetapan waktu alir granul rata-rata 9,47 detik/100 g SD=0,460 (syarat tidak lebih $10 \mathrm{detik} / 100 \mathrm{~g}$ ). Hasil ini menunjukkan bahwa granul memiliki kecepatan bergulir yang baik, hal ini berpengaruh pada proses penyalutan granul dan pada saat pengisian granul ke dalam cangkang kapsul, yang dapat mempengaruhi keragaman bobo kapsul.

Hasil evaluasi sudut diam granul rata-rata 19,62 derajat, memenuhi syarat tidak lebih dari 30 derajat menurut Lachman. Granul dengan sudut diam yang baik diharapkan menghasilkan kapsul dengan bobot yang seragam.

Hasil evaluasi kompresibilitas granul ratarata $15,33 \% \mathrm{SD}=0,577$, memenuhi syarat 5 $16 \%$ menurut Lachman dan Aulton. Hasil ini digunakan pada perhitungan penetapan bobot jenis granul.

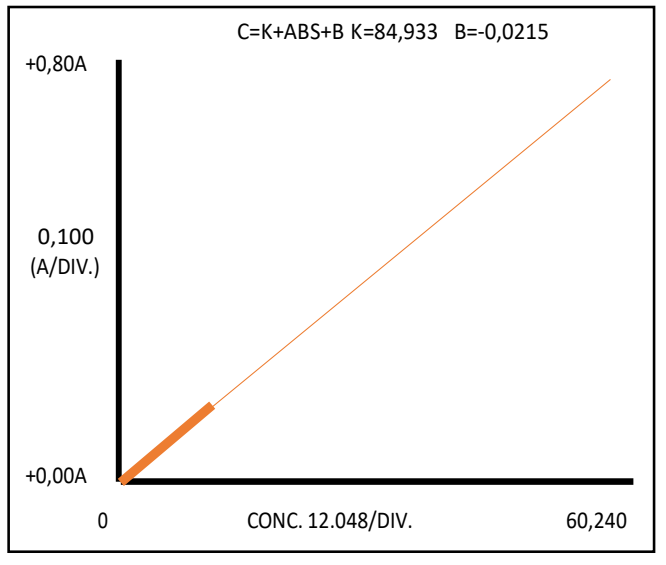

Gambar 3. Kurva kalibrasi GG (kloroform)

Hasil penetapan bobot jenis granul ratarata $0,69 \mathrm{~b} / \mathrm{v} \mathrm{SD}=0,008$. Hasil ini digunakan untuk memilih ukuran cangkang kapsul yang digunakan pada formulasi kapsul.

Hasil penetapan keseragaman derajat halus granul rata-rata $10,31 \% \mathrm{SD}=1,374$, memenuhi syarat serbuk sangat kasar tidak lebih dari $20 \%$ lewat ayakan No.60 menurut Farmakope Indonesia Edisi IV. Hasil ini untuk mengetahui seberapa banyak serbuk halus yang ada dalam sejumlah bobot granul.

Hasil evaluasi distribusi ukuran granul diperoleh rata-rata pada ayakan No. $10(2,00$ $\mathrm{mm})$ adalah 4,83\%; pada ayakan No. $14(1,40$ $\mathrm{mm})$ adalah 11,97\%; pada ayakan No. $16(1,18$ $\mathrm{mm})$ adalah 55,19\%; pada ayakan No. $18(1,00$ $\mathrm{mm})$ adalah 16,29\%; pada ayakan No. $60(0,25$ $\mathrm{mm}$ ) adalah $10,08 \%$. Hasil evaluasi distribusi ukuran granul salut HPMCP 10\% diperoleh rata-rata pada ayakan No. $10(2,00 \mathrm{~mm})$ adalah 26,97\%; pada ayakan No. $14(1,40 \mathrm{~mm})$ adalah 50,75\%; pada ayakan No. $16(1,18 \mathrm{~mm})$ adalah 18,58\%; pada ayakan No. $18(1,00 \mathrm{~mm})$ adalah $3,26 \%$; pada ayakan No. $60(0,25 \mathrm{~mm})$ adalah $0 \%$. Hasil ini menunjukkan bahwa uuran granul setelah disalut mengalami penigkatan dari ukuran granul sebelum disalut, hal ini disebabkan karena penyelimutan lapisan polimer pada permukaan granul. Hasil distribusi ukuran granul dan granul salut menunjukkan distribusi normal ukuran granul, sesuai dengan distribusi granul yang ideal. Hal ini disebabkan karena pembuatan granul dengan sistem pengayakan bertingkat.

Hasil evaluasi homogenitas granul diperoleh rata-rata $100,11 \%$; $\mathrm{RSD}=0,583$, menunjukkan bahwa bahan berkhasiat terdistribusi secara merata dalam granul-granul yang dibuat. 
Hasil evaluasi homogenitas pada granul salut, menunjukkan bahwa ada kerusakan warna pada Formula B dan Formula C. Hal ini disebabkan karena larutan penyalut pada Formula B dan Formula C terlalu encer, sehingga tidak meratanya distribusi larutan penyalut pada permukaan granul untuk membentuk lapisan tipis dan menyebabkan pelembababn setempat. Selain kekentalan, distribusi larutan penyalut dipengaruhi teknik penyalutan, hal ini dibuktikan dengan mengatur jumlah, kecepatan, dan atomisasi larutan penyalut yang keluar dari alat semprot dapat dihasilkan penyalutan yang merata, serta pemilihan zat warna yang sesuai dengan pelarut yang digunakan.

Hasil evaluasi penetapan kadar granul GG dan granul salut GG diperoleh rata-rata Formula A adalah 100,09\%, RSD $=0,262$; Formula B adalah 99,12\%, RSD $=0,243$; Formula $\mathrm{C}$ adalah 98,82\%, RSD $=0,333$; Formula $\mathrm{D}$ adalah 94,15\%, RSD-0,373; dan Formula E adalah $90,33 \%, \mathrm{RSD}=0,747$; memenuhi syarat menurut Farmakope Indonesia Edisi IV, yaitu: 90,0$110,0 \%$. Pada penetapan kadar granul salut terlihat penurunan kadar GG berbanding lurus dengan besarnya konsentrasi bahan penyalut yang digunakan, hal ini karena bahan penyakut yang digunakan dapat meningkatkan bobot granul salut.

Hasil uji disolusi kapsul Formula A, Formula B, Fornula C, Formula D, dan Formula E; kapsul Formula A, Formula B, dan Formula $\mathrm{C}$ pelepasan obat dimulai menit ke-0, sedangkan kapsul Formula D pelepasan obat dimulai setelah 1 jam dan kapsul Formula E pelepasan obat dimulai setelah 3 jam. Formula A dilepaskan obat $100,1 \%$ setelah 60 menit, Formula B dilepaskan obat $99,0 \%$ setelah 120 menit, Formula C dilepaskan obat $96,47 \%$ setelah 240 menit, Formula D dilepaskan obat 92,16\% setelah 480 menit, dan Formula E dilepaskan obat $78,59 \%$ setelah 720 menit, sehingga kapsul yang mengandung Formula A, yaitu granul tidak disalut dapat dijadikan sebagai dosis awal untuk membuat kapsul dengan pelepasan terkendali, dan kapsul yang mengandung Formula D dan Formula E dengan memvariasikan dosisnya dapat dijadikan sebagai dosis penjagaan untuk membuat kapsul dengan pelepasan terkendali. Granul GG dan granul salut GG dengan berbagai variasi konsentrasi bahan penyalut HPMCP dapat memberikan profil pelepasan obat dengan waktu dan jumlah yang berbeda. Berdasarkan data di atas, maka dapat dibuat kapsul Formula
1, Formula 2, Formula 3, Formula 4, Formula 5, dan Formula 6 dengan pelepasan terkendali yang mengandung granul Formula A sebagai dosis awal dan dengan variasi granul Formula D dan Formula E sebagai dosis penjagaan.

Hasil evaluasi waktu hancur kapsul Formula 1, Formula 2, Formula 3, Formula 4, Formula 5, dan Formula 6, memenuhi syarat Farmakope Indonesia Edisi IV, yaitu waktu hancur kapsul tidak lebih dari 15 menit. Pada tiap formula kapsul tidak terlihat perbedaan waktu hancur karena jenis cangkang kapsul yang digunakan sama.

Hasil evaluasi keragaman bobot kapsul Formula 1, Formula 2, Formula 3, Formula 4, Formula 5, dan Formula 6, memenuhi kriteria menurut Farmakope Indonesia Edisi IV, yaitu sejumlah obat 9 dari 10 kapsul terletak antara $85,0-115,0 \%$ dari etiket dan tidak ada kapsul yang terletak diluar rentang $75-115 \%$ dari etiket dan RSD kurang atau sama dengan 6,0\%. Hasil menunjukkan bahwa semua kapsul tiap formula memiliki bobot yang sama sesuai dengan etiket.

Hasil evaluasi homogenitas campuran granul Formula 1 diperoleh rata-rata 99,97\%, Formula 2 diperoleh rata-rata $96,19 \%$, Formula 3 diperoleh rata-rata $95,62 \%$, Formula 4 diperoleh rata-rata $94,95 \%$, Formula 5 diperoleh rata-rata $94,13 \%$, dan Formula 6 diperoleh rata-rata $93,53 \%$. Hasil ini menunjukkan bahwa campuran granul dari tiap formula homogen, hal ini disebabkan karena penimbangan dari tiap formula yang tepat dan pencampuran secara manual yang merata.

Hasil penetapan kadar rata-rata kapsul Formula 1, Formula 2, Formula 3, Formula 4, Formula 5, dan Formula 6, memenuhi syarat menurut Farmakope Indonesia Edisi IV, yaitu: 90,0-110,0\% terhadap etiket dan RSD kurang atau sama dengan $6,0 \%$. Hasil penetapan kadar pada tiap formula kapsul berlainan karena tiap formula memiliki komposisi perbandingan formula granul yang berbeda.

Hasil uji disolusi penelitian ini sejalan dengan penelitian Dou, dan kawan-kawan, 2019, bahwa penyalutan multigranul dapat memberikan pelepasan berkelanjutan yang jelas dan peningkatan ketersediaan hayati. Hasil akhir tiap formula kapsul sesuai dengan komposisi perbandingan granul Formula A, granul Formula D, dan granul Formula E; Formula 1 obat terlarut adalah $99,99 \%$ setelah 1 jam, obat dilepaskan seperti sediaan konvensional, tidak ada mekanisme pelepasan obat secara terkendali, dan dapat menyebabkan kelebihan dosis karena jumlah obat yang 
dilepas mengandung 3 kali dosis awal dari pelepasan terkendali. Formula 2 obat terlarut adalah $95,37 \%$ setelah 8 jam, obat dilepaskan secara terkendali, tetapi tidak mengandung dosis ketiga, yaitu granul Formula E, sehingga pelepasan obat terjadi hanya 2 kali. Formula 3, Formula 4, dan Formula 5 obat terlarut adalah 92,88\%; 91,49\%; dan 89,20\% setelah 12 jam, obat dilepaskan secara terkendali yang ideal, dimana obat dilepaskan secara terus-menerus tanpa henti mulai dari awal pelepasan obat sampai obat dilepaskan seluruhnya. Formula 6 obat terlarut adalah $87,68 \%$ setelah 12 jam, obat dilepaskan tidak secara terkendali karena tidak mengandung dosis kedua, yaitu granul Formula $\mathrm{D}$, sehingga ada jarak waktu yang cukup lama sebelum dosis ketiga dilepaskan secara bertahap terhadap dosis awal, hal ini menyebabkan tidak terpenuhinya dosis pada jarak waktu tersebut.

Uji disolusi tahap akhir adalah disolusi kapsul yang mengandung campuran 3 jenis granul (Formula A + Formula D + Formula E). Komposisi kapsul divariasikan berdasarkan dosis penjagaannya.

Berdasarkan hasil uji disolusi dibuat kapsul GG yang dapat memberikan profil pelepasan obat secara terkendali dalam jarak waktu lama dan jumlah obat terlarut yang besar.

Tabel 2. Komposisi Kapsul GG

\begin{tabular}{|c|c|c|c|}
\hline \multirow{2}{*}{$\begin{array}{c}\text { FORMULA } \\
\text { KAPSUL }\end{array}$} & \multicolumn{3}{|c|}{ KADAR GLISERIL GUAIAKOLAT(MG) } \\
\cline { 2 - 4 } & FORMULA A & FORMULA D & FORMULA E \\
\hline 1 & 300 & 0 & 0 \\
\hline 2 & 100 & 200 & 0 \\
\hline 3 & 100 & 150 & 50 \\
\hline 4 & 100 & 100 & 100 \\
\hline 5 & 100 & 50 & 150 \\
\hline 6 & 100 & 0 & 200 \\
\hline
\end{tabular}

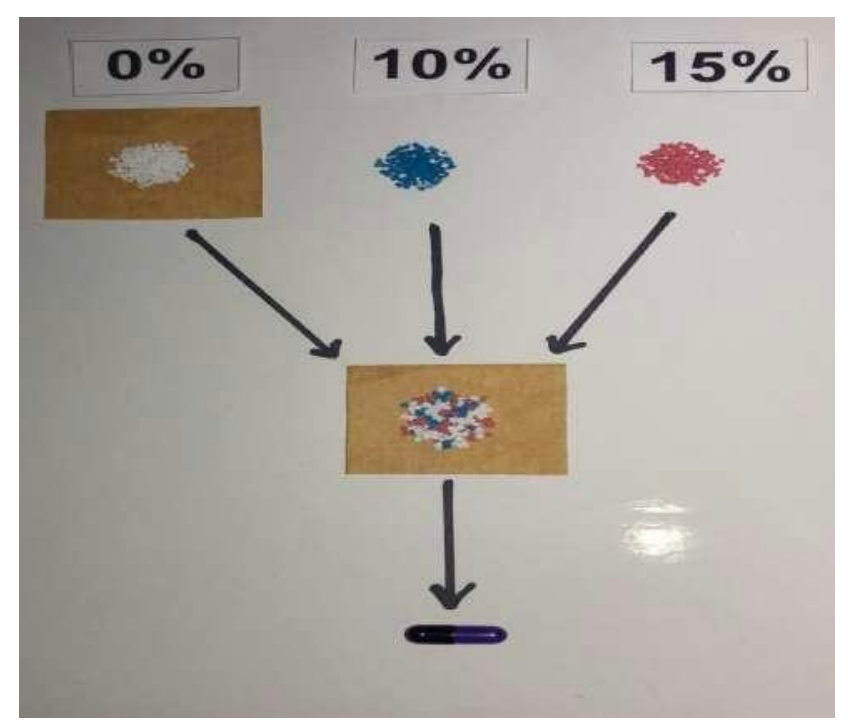

Gambar 4. Hasil Pembuatan Kapsul GG 
66 Wirabrata et al., (Formulasi Multigranul Salut Film Dalam Kapsul...)

Tabel 3. Hasil Uji Disolusi Kapsul Formula 1, 2, 3, 4, 5, dan 6

\begin{tabular}{|c|c|c|c|c|c|c|c|c|c|c|c|c|c|}
\hline \multirow{3}{*}{ No. } & \multirow{3}{*}{ Menit ke- } & \multicolumn{12}{|c|}{ Jumlah obat terlanut (\%) } \\
\hline & & \multicolumn{2}{|c|}{ Formula 1} & \multicolumn{2}{|c|}{ Formula 2} & \multicolumn{2}{|c|}{ Formula 3} & \multicolumn{2}{|c|}{ Formula 4} & \multicolumn{2}{|c|}{ Formula 5} & \multicolumn{2}{|c|}{ Formula 6} \\
\hline & & Rata-rata & RSD & Rata-rata & RSD & Rata-rata & RSD & Rata-rata & RSD & Rata-rata & RSD & Rata-rata & RSD \\
\hline (1) & 60 & 99,99 & 0,076 & 33,40 & 0,076 & 33,38 & 0,015 & 33,38 & 0,006 & 33,37 & 0,176 & 33,39 & 0,089 \\
\hline 2. & 120 & & & 60,27 & 0,107 & 53,25 & 0,401 & 46,76 & 0,107 & 40,25 & 0,258 & 33,43 & 0,047 \\
\hline 3. & 180 & & & 73,93 & 0,089 & 63,19 & 0,274 & 53,65 & 0,108 & 43,40 & 0,131 & 33,51 & 0,191 \\
\hline 4. & 240 & & & 82,41 & 0,082 & 72,08 & 0,063 & 62,56 & 0,003 & 53,94 & 0,198 & 42,56 & 0,137 \\
\hline 5. & 300 & & & 87,08 & 0,009 & 79,35 & 0,059 & 72,67 & 0,192 & 65,63 & 0,179 & 58,36 & 0,015 \\
\hline 6. & 360 & & & 91,25 & 0,074 & 84,50 & 0,169 & 78,56 & 0,248 & 72,74 & 0,102 & 66,65 & 0,105 \\
\hline 7. & 420 & & & 94,24 & 0,077 & 88,57 & 0,092 & 83,67 & 0,004 & 77,29 & 0,261 & 72,54 & 0,011 \\
\hline Q & 480 & & & 94,72 & 0,009 & 90,63 & 0,015 & 86,70 & 0,003 & 82,06 & 0,094 & 78,33 & 0,011 \\
\hline 9. & 540 & & & 94,85 & 0,900 & 91,73 & 0,089 & 89,13 & 0,082 & 85,42 & 0,030 & 82,85 & 0,095 \\
\hline 10. & 600 & & & 95,14 & 0,860 & 92,13 & 0,091 & 89,78 & 0,012 & 86,83 & 0,003 & 84,03 & 0,236 \\
\hline 11. & 660 & & & 95,32 & 0,007 & 92,38 & 0,093 & 90,46 & 0,025 & 87,24 & 0,091 & 84,69 & 0,009 \\
\hline (2) & 720 & & & 95,32 & 0,134 & 92,88 & 0,088 & $\underline{91,49}$ & 0,002 & 89,20 & 0,081 & $\underline{87,68}$ & 0,092 \\
\hline
\end{tabular}

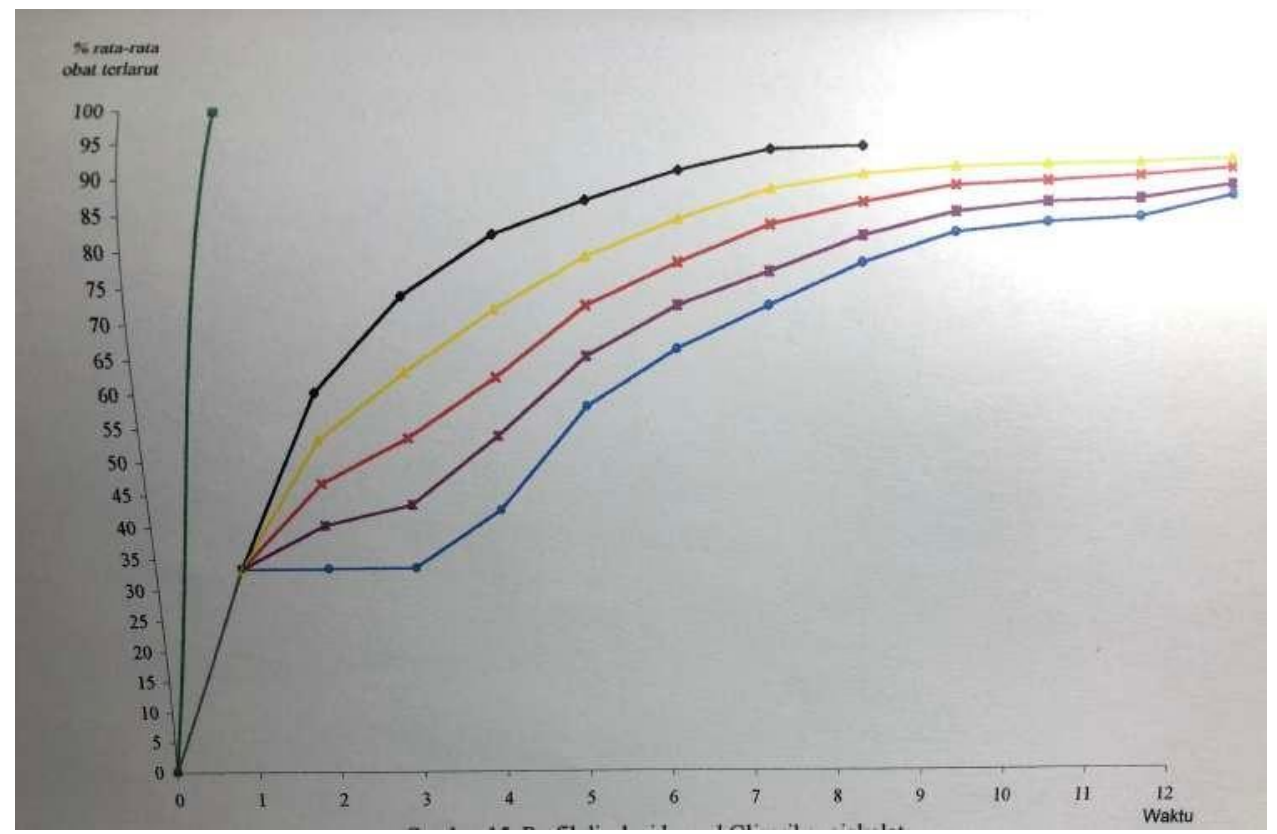

Keterangan gambar:

Hijau: Formula $1=3$ Formula $\mathrm{A}$

Hitam: Formula $2=1$ Formula A +2 Formula D

Kuning: Formula $3=1$ Formula A $+1,5$ Formula D $+0,5$ Formula E

Merah: Formula $4=1$ Formula A +1 Formula D +1 Formula E

Ungu: Formula $5=1$ Formula $A+0,5$ Formula $D+1,5$ Formula $E$

Biru: Formula $6=1$ Formula $A+2$ Formula $E$

Gambar 5. Profil Disolusi Kapsul GG 


\section{SIMPULAN}

Granul tidak disalut dan granul salut GG dengan berbagai variasi konsentrasi bahan penyalut hidroksipropil metilselulosa ftalat dapat memberikan profil pelepasan obat dengan waktu dan jumlah yang berbeda. Pelepasan obat Formula A (granul tidak disalut) dimulai menit ke- 0 selama 60 menit, pelepasan obat Formula B (granul salut HPMCP $1 \%$ ) dimulai menit ke-0 selama 120 menit, pelepasan obat Formula C (granul salut HPMCP 5\%) dimulai menit ke-0 selama 240 menit, pelepasan obat Formula D (granul salut HPMCP 10\%) dimulai setelah 60 menit selama 480 menit, dan pelepasan obat Formula E (granul salut HPMCP 15\%) semulai setelah 180 menit selama 720 menit.

Kapsul Formula 3 (1 Formula A + 1,5 Formula D $+0,5$ Formula E) dapat memberikan profil pelepasan GG secara terkendali selama 12 jam dengan jumlah GG yang terbesar, yaitu: 92,9\%. Kapsul Formula 4 (1 Formula $\mathrm{A}+1$ Formula $\mathrm{D}+1$ Formula $\mathrm{E})$ dan Formula 5 (1 Formula A $+0,5$ Formula D $+1,5$ Formula E) dapat memberikan profil pelepasan GG secara terkendali selama 12 jam dengan jumlah GG terlarut $91,5 \%$ dan $89,2 \%$.

\section{UCAPAN TERIMA KASIH}

Peneliti menghaturkan banyak terima kasih kepada seluruh pihak yang membantu selama proses penelitian, pimpinan dan segenap civitas-akademika Fakultas Farmasi Universitas Pancasila, serta pimpinan dan bagian produksi Lembaga Farmasi Angkatan Laut.

\section{PENGAKUAN}

Penelitian ini dibuat dan selesai pada tahun 2000 dengan menggunakan alat-alat sederhana, namun memenuhi standar persyaratan alat pembuatan kapsul multigranul salut film sesuai literatur dan pengujian-pengujian standar dikerjakan laboratorium terakreditasi.

\section{DAFTAR PUSTAKA}

[1] Departemen Kesehatan RI, 1995, Farmakope Indonesia Edisi IV, Ditjen POM, Jakarta, hal. 2-4, 108, 421-423, 515, 771, 9991001, 1044, 1083-1086, dan 1163.

[2] Dou, Yinghuan., Li Xuefeng., Shi Yanbin., Zhang Jiaying., 2019, Preparation, Optimization and In Vitro- In Vivo Evaluation of Shunxin
Sustained Release Granules. Jouirnal Chinese Medicine 14. Article Number 36. Page 1-5.

[3] Velghe, Carine. 2019. Oral Controlled Drug Delivery System, Optimization Of Release Patterns and Elucidation of Relase Mechanisms. Universite du Droit et de la Sante - Lille II. France.

[4] Patel, Sandipkumar., Patel, Nrupa., Misra Manju., Joshi Abhijeet. 2018. ControlledRelease Domperidone Pellets Compressed Intu Fast Disintegrating Tablets Forming A Multiple-Unit Pellet System (MUPS). Journal of Drug Delivery Science and Technology. Elsevier. Page1-3.

[5] Keen, Justin M., Foley Conner J., Hughey, Justin R., Bennett Ryan C. 2015. Continuous Twin Screw Melt Granulation of Glyceryl Behenate: Development of Controlled Release Tramadol Hydrochloride Tablets For Improve Safety. International Journal of Pharmaceutics. Elsevier. Vol. 487. Issues 1-2. Page. 72-80.

[6] Nikolakakis, Ioannis. 2017. SelfEmulsifying Granules and Pellets: Composition and Formation Mechanisms For Instant of Controlled Release. Journal Pharmaceutics. Vol. 9. Issue 4. Page. 10-15.

[7] Gennaro, A. R., 1995, Remington's Pharmaceuticals Sciences, $19^{\text {th }}$ Edition, Mack Publishing Co., Easton-Pensylvania, hal. 16521653.

[8] Macleaod, Graeme S., Collett John H., Fell T., The Potential Use Of Mixed Films of Pectin, Chitosan And HPMC For Bimodal Drug Release, Journal of Control Realease, Elsevier, Volume 58, page 303-310.

[9] Narisawa, S., Nagata M., Ito T., Yoshino H., Hirakawa Y., Noda k., 1995, Drug Release Behavior In Gastrointestinal Tract Of Beagle Dogs From Multiple Unit Type Rate-Controlled Or Time-Controlled Release Preparations Coated With Insoluble Polymer-Based Film, Journal of Control Realease, Elsevier, Volume 33, page 253-260.

[10] Nokhodchi, Ali., Raja Shaista., Patel Pryia., Addo Kofi. 2012. The Role of Oral Controlle Release Matrix Tablets in Drug Delivery System. US National Library of Medicine National Institutes of Health. BioImpacts.

[11] Ottenbrite, Raphael. 2010. Biomedical Application if Hydrogels Handbook. Springer New York. Page 121-124, 147-150.

[12] Robinson, Joseph R.; Lee, Vincent H. L., Controlled Drug Delivery, edisi 2, Marcel Dekker Inc., New York, hal 179-210, dan 255258. 
68 Wirabrata et al., (Formulasi Multigranul Salut Film Dalam Kapsul...)

[13] Safdar, Rizwan. Omar, Abdul Aziz., Arunagiri, Appusami. 2019. Potential of Chitosan and Its Derivatives For Controlled Drug Release Application. Journal of Drug Delivery Science and Technology. Vol. 49. Pages 642-659.

[14] Siepmman J., Lecomte F., Bodmeier R., 1999, Diffusion-Controlled Drug Delivery Systems: Calculation of The Required Composition To Achieve Desired Release Profiles, Journal of Control Realease, Elsevier, Volume 60, page 379-389.

[15] United States Phamacopeia Convention Inc., 1995, The United States Phamacopeia XXIII and The National Formulary, $18^{\text {th }}$ Rev., Rockville, hal. 131-135, 785-786, 1573-1574, dan 2231.

[16] Voigt, R., 1994, Buku Pelajaran Teknologi Farmasi, Edisi 5, ahli bahasa: Noerono, S., Gadjah Mada University Press, Yogyakarta, hal. 10, 14, 169, 171-179, 201-207, 227-229, 239-248, 267-276, dan 769-785.

[17] Zarmi, P., Flanagan., Meehan E. 2017. Biopharmaceutical Aspects And Implication of Exipient Variability In Drug Product Performance. Vol. 111 Pages 1-15. Elsevier. 